\title{
Article
}

Subscriber access provided by Caltech Library Services

\section{Computational design of a pincer phosphinito vanadium ((OPO)V) propane monoxygenation homogeneous catalyst based on the reduction-coupled oxo activation (ROA) mechanism.}

Ross Fu, William A. Goddard, Mu-Jeng Cheng, and Robert J. Nielsen

ACS Catal., Just Accepted Manuscript • DOI: 10.1021/acscatal.6b02781 • Publication Date (Web): 28 Nov 2016

Downloaded from http://pubs.acs.org on November 29, 2016

\section{Just Accepted}

"Just Accepted" manuscripts have been peer-reviewed and accepted for publication. They are posted online prior to technical editing, formatting for publication and author proofing. The American Chemical Society provides "Just Accepted" as a free service to the research community to expedite the dissemination of scientific material as soon as possible after acceptance. "Just Accepted" manuscripts appear in full in PDF format accompanied by an HTML abstract. "Just Accepted" manuscripts have been fully peer reviewed, but should not be considered the official version of record. They are accessible to all readers and citable by the Digital Object Identifier (DOI®). "Just Accepted" is an optional service offered to authors. Therefore, the "Just Accepted" Web site may not include all articles that will be published in the journal. After a manuscript is technically edited and formatted, it will be removed from the "Just Accepted" Web site and published as an ASAP article. Note that technical editing may introduce minor changes to the manuscript text and/or graphics which could affect content, and all legal disclaimers and ethical guidelines that apply to the journal pertain. ACS cannot be held responsible for errors or consequences arising from the use of information contained in these "Just Accepted" manuscripts. 


\title{
Computational design of a pincer phosphinito vanadium ((OPO)V) propane monoxygenation homogeneous catalyst based on the re- duction-coupled oxo activation (ROA) mechanism.
}

\author{
Ross Fu, William A. Goddard III, ${ }^{*}$ Mu-Jeng Cheng, and Robert J. Nielsen. \\ Materials and Process Simulation Center (139-74) \\ California Institute of Technology, Pasadena, CA 91125 USA.
}

\begin{abstract}
We propose the vanadium bis(2-phenoxyl)phosphinite pincer complex, denoted (OPO)V, as a low temperature water-soluble catalyst for monoxygenation of propane to isopropanol with functionalization and catalyst regeneration using molecular oxygen. We use DFT study to predict that the barrier for (OPO)V to activate the secondary hydrogen of propane is $\Delta G^{\sharp}=25.2$ $\mathrm{kcal} / \mathrm{mol}$ at $298 \mathrm{~K}$, leading to isopropanol via the new reduction-coupled oxo activation (ROA) mechanism. We then show that reoxidation by dioxygen to complete the cycle is also favorable with $\Delta G^{\sharp}=6.2 \mathrm{kcal} / \mathrm{mol}$ at $298 \mathrm{~K}$. We conclude that (OPO) $\mathrm{V}$ represents a promising homogeneous catalyst for the monoxygenation of propane and other alkanes (including ethane), warranting experimental validation.
\end{abstract}

\section{KEYWORDS Homogeneous catalysis, pincer ligand, alkane $C-H$ activation, density functional theory, vanadium, alkane oxidation}

\section{INTRODUCTION}

Vanadium phosphorus oxide (VPO) is an inorganic compound that catalyzes the oxidation of $n$-butane to maleic anhydride with a surprisingly high selectivity of $60-70 \%{ }^{1}$ Although the overall yield is only about $50 \%$, its ease of synthesis, use of common elements, and selectivity have led to commercial success for this catalyst, producing approximately 500 kilotons of maleic anhydride annually. ${ }^{2}$

The reaction mechanism underlying this remarkable catalyst remained a mystery until our previous DFT computational studies on this system, in which we found that the initial C-H activation of the butane substrate occurred at the phosphorus oxo moiety, in contrast to conventional wisdom that assumed the activation to be at the $\mathrm{V}=\mathrm{O}$ center. ${ }^{3}$ We predicted that the activation energy for the initial activation of the $\mathrm{C}-\mathrm{H}$ bond is $13.6 \mathrm{kcal} / \mathrm{mol}$, and our analysis of all 14 steps leading to the maleic anhydride product predicted barriers less than 23 $\mathrm{kcal} / \mathrm{mol}$, all within the experimental range of 12.9-23.6 $\mathrm{kcal} / \mathrm{mol}^{4}{ }^{4}$ We used DFT to show that the remarkably low activation barrier for attack by a $\mathrm{P}=\mathrm{O}$ bond on the $\mathrm{C}-\mathrm{H}$ bond of an alkane arises from the localization of the unpaired spin on the neighboring vanadium atom(s) (Figure 1), rather than on the phosphorus.

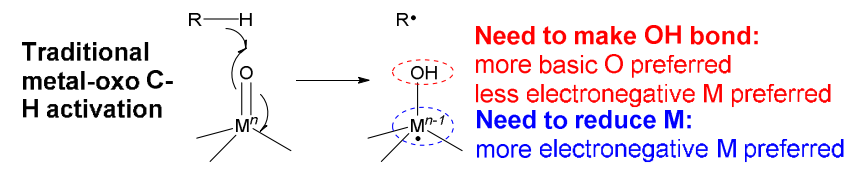

ROA<smiles>CCOC(=O)OC(C)(C)OCC</smiles>

R.<smiles>CC(=O)O[V](C)(C)O</smiles>

basicity and electron affinity decoupled onto different elements
Figure 1. C-H activation by a phosphorus oxo coupled to a $\mathrm{V}^{\mathrm{V}}$, leads to a one electron reduction on the neighboring vanadium. Hence the oxidation state of the phosphorus atom does not change. This is the Reduction-Coupled Oxo Activation (ROA) mechanism.

Our interpretation of this surprising discovery of $\mathrm{C}-\mathrm{H}$ activation ability by $\mathrm{P}^{\mathrm{V}}=\mathrm{O}$ moieties on the $\mathrm{V}^{\mathrm{V}} \mathrm{OPO}_{4}$ surface ${ }^{5}$ led to our formulating the Reduction-Coupled Oxo Activation (ROA) mechanism to describe this phenomenon. ${ }^{6} \mathrm{C}-\mathrm{H}$ activation ideally prefers maximizing both basicity and electron affinity, since $\mathrm{H}$-atom transfer involves both proton and electron transfer. This is not possible for a simple transition metal oxo bond, since increasing the basicity of the oxygen also increases the neighboring metal's electron density, thereby decreasing its electron affinity. In the ROA mechanism, a transition metal oxo (with high electron affinity) is placed in communication with a group 15 or 16 metal oxo (with high basicity) such as $\mathrm{P}$, $\mathrm{As}, \mathrm{Sb}, \mathrm{Bi}, \mathrm{Se}$, or Te. By keeping the sites of basicity and reduction on separate moieties, ROA is able to decouple the $\mathrm{C}-$ $\mathrm{H}$ activation process into addition of the proton on the $\mathrm{P}=\mathrm{O}$ along with addition of the electron to the $\mathrm{V}^{\mathrm{V}}$, allowing the best of both worlds with high basicity and high electron affinity.

More recently, we showed that this ROA mechanism is also responsible for the remarkable activation of propane during ammoxidation via the $\mathrm{MoVNbTeO}_{x}$ catalysts. Here it is a $\mathrm{Te}=\mathrm{O}$ bond that does the propane activation, but only when coupled to one or more reducible $\mathrm{V}=\mathrm{O}$ centers. ${ }^{4,6}$ Indeed, a great many heterogeneous selective oxidation catalysts combine a group 15 or 16 metalloid such as $\mathrm{P}, \mathrm{As}, \mathrm{Sb}, \mathrm{Bi}, \mathrm{Se}$, or $\mathrm{Te}$ with reducible metals such as $\mathrm{Mo}^{\mathrm{VI}}$ and $\mathrm{V}^{\mathrm{V}}$, suggesting that ROA may be a general principle for heterogeneous selective oxidation of alkanes. ${ }^{6 b}$ 
However, we know of no cases of homogeneous catalysts that operate via ROA. It would be useful to find such homogeneous catalysts since they might provide new generations of catalysts for selective oxidation of alkanes, and since they might provide better systems for detailed experimental tests of the ROA mechanism. In our previous report, we sought to design a homogeneous oxidation catalyst that utilizes the ROA mechanism as shown in Figure $1 .^{7} \mathrm{We}$ examined various group $5(\mathrm{~V}, \mathrm{Nb}, \mathrm{Ta})$ and group $10(\mathrm{Ni}, \mathrm{Pd}, \mathrm{Pt})$ complexes with XPX pincer ligands (where $X=N, O, P, S$ ). Since homogeneous complexes containing a $\mathrm{P}(\mathrm{O})-\mathrm{O}-\mathrm{V}(\mathrm{O})$ moiety (as shown in Figure $2 \mathrm{a}$ ) are very rare in the literature, owing to their difficulty in synthesis, ${ }^{8}$ we explored complexes incorporating an alternative metal core featuring a direct V-P bond (as in Figure $2 b)$. (a) $\mathrm{R}$

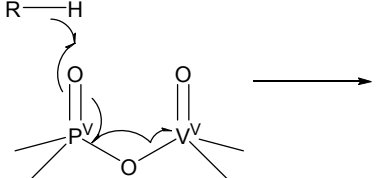

(b)

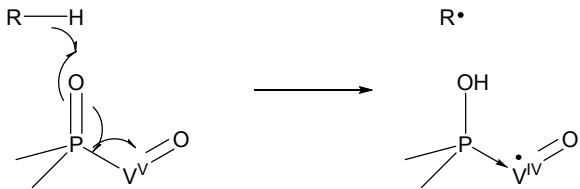

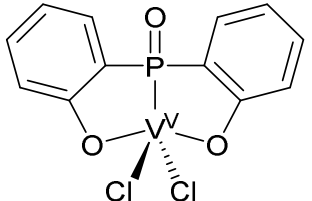

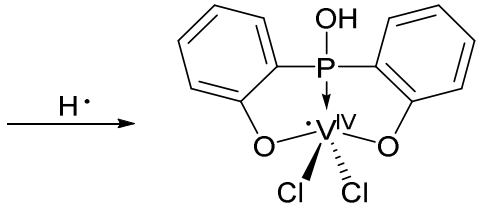

Scheme 1. (OPO) $\mathrm{V}^{\mathrm{V}} \mathrm{Cl}_{2}$ (left) can add a hydrogen atom to form $\mathrm{H}(\mathrm{OPO}) \mathrm{V}^{\mathrm{IV}} \mathrm{Cl}_{2}$ (right). The enthalpy change is $\mathbf{- 8 5 . 6}$ $\mathrm{kcal} / \mathrm{mol}$ and the $\mathrm{V}-\mathrm{P}$ bond lengthens from $2.52 \AA$ to 2.64 A. Numbers taken from our prior study. ${ }^{7}$

In this contribution, we examine our $(\mathrm{OPO}) \mathrm{V}$ complexes in much more depth using density functional theory to flesh out a complete catalytic cycle. To simplify our calculations, we use propane as our alkane substrate since it forms the symmetrical isopropyl radical. We show that $(\mathrm{OPO}) \mathrm{V}$ in aqueous solution forms a resting state with an oxo and hydroxo ligand $\left((\mathrm{OPO})_{\mathrm{H}} \mathrm{V}^{\mathrm{V}} \mathrm{O}^{s}(\mathrm{OH})^{a}\right.$ in our nomenclature, which will be explained below), and that this complex utilizes the reductioncoupled oxo activation (ROA) mechanism in the catalytic oxidation of propane to isopropanol using dioxygen as the oxidant. We describe the most plausible transition state barriers for this conversion. These theoretical findings suggest that this molecule will provide catalytic ability in heretofore unseen in homogeneous catalysis.

\section{MATERIALS AND METHODS}

\section{General calculations}

Figure 2. (a) Vanadium-phosphate archetype: conceptual arrowpushing scheme for $\mathrm{P}-\mathrm{V}$ electron transfer with an intervening $\mu$ oxo. (b) Vanadium- $\kappa$-P-phosphinite archetype: conceptual arrowpushing scheme for $\mathrm{P}-\mathrm{V}$ electron transfer in which they are directly bound to each other.

Complexes featuring such $\kappa$-P phosphinite coordination to metals including $\mathrm{Co}^{9}, \mathrm{Ni}^{10}, \mathrm{Pd}^{11}$, and $\mathrm{Pt}^{12}$ have been described. In addition, many other complexes containing a phosphido ligand bonded to metals such as $\mathrm{Co}^{9}, \mathrm{Rh}^{13}, \mathrm{Pd}^{13},{ }^{14}, \mathrm{Ir}^{15}$, and $\mathrm{Pt}^{12,13,16}$ have also been described. These phosphido complexes are a single monoxygenation step away from the corresponding phosphine oxide complexes, a transformation we expect to be facile due to the large formation energy of phosphine-oxo bonds. Indeed a few such complexes have been reported. ${ }^{9,12}$

Our prior investigation led to the proposal that the ligand bis(2-phenoxyl)phosphinite $\kappa$-P coordinated on vanadium, abbreviated (OPO) $\mathrm{V}$, is a candidate catalyst for $\mathrm{C}-\mathrm{H}$ activation (Scheme 1). We expect that this complex should be robust based on factors such as the chelation effect, the stability of $\mathrm{O}-\mathrm{V}$ bonds, and the rigidity of the ligand, which guards against insertion of small activating molecules into the $\mathrm{V}-\mathrm{P}$ bond. Scheme 1 shows our best candidate, $(\mathrm{OPO}) \mathrm{V}^{\mathrm{V}} \mathrm{Cl}_{2}$, which has a $D_{\mathrm{H}}$ value of $85.6 \mathrm{kcal} / \mathrm{mol}$ (where $D_{\mathrm{H}}$, a measure of H-atom affinity, is defined as the enthalpy change when the $\mathrm{O}-\mathrm{H}$ bond in $\mathrm{M}-\mathrm{O}-\mathrm{H}$ is homolytically cleaved to form the $\mathrm{M}=\mathrm{O}$ oxo), which compares favorably with the $D_{\mathrm{H}}=84.3$ $\mathrm{kcal} / \mathrm{mol}$ for VPO. ${ }^{6 \mathrm{a}}$ Since the bond enthalpy of secondary C$\mathrm{H}$ bonds in alkanes is $\sim 98 \mathrm{kcal} / \mathrm{mol}$, the activation enthalpies are expected to be $\sim 20 \mathrm{kcal} / \mathrm{mol},{ }^{17}$ which is sufficiently low to be accessible at temperatures below $150^{\circ} \mathrm{C}$.
All quantum mechanical calculations were carried out using the Jaguar software version 7.9 developed by Schrödinger Inc. ${ }^{18}$ Geometry optimizations were carried out on initial guess structures, and vibrational frequencies were calculated to confirm the optimized geometries as intermediates (no negative curvatures) or transition states (one negative curvature) and to calculate the zero-point energy, entropy, and temperature corrections in order to obtain the free energy profile. Solvation energies were calculated using the PBF Poisson-Boltzmann implicit continuum solvation mode ${ }^{19}$ in Jaguar, with a dielectric constant of 80.37 and a probe radius of $1.40 \AA$, based on water.

Calculations were performed using the B3LYP density functional $^{20}$ with the Grimme post-SCF D3 correction for van der Waals interactions. ${ }^{21}$ Geometry optimization and vibrational frequencies were calculated using the double- $\zeta$ basis set 6 $31 \mathrm{G}^{* * 22}$ for all elements except vanadium, and the double- $\zeta$ basis set and pseudopotential LACVP** for vanadium. ${ }^{23}$ Single point gas-phase and solvated energies were calculated using the triple- $\zeta$ Los Alamos basis set and pseudopotential (LACV3P**++) modified to include $f$ functions and diffuse functions for vanadium, ${ }^{24}$ and the $6-311 \mathrm{G}^{* *++}$ basis $\operatorname{set}^{25}$ for the other atoms. For orbital analysis, we used the Pipek-Mezey localization procedure. ${ }^{26}$ All calculations were performed with a temperature of $298.15 \mathrm{~K}\left(25^{\circ} \mathrm{C}\right)$.

\section{Construction of the free energy}

The free energy for each vanadium species in solution was calculated using the formula $G=E_{\text {gas }}+\Delta E_{\text {solv }}+\mathrm{ZPE}+H_{\mathrm{vib}}+$ $6 k T-T\left[S_{\text {vib }}+0.54\left(S_{\text {trans }}+S_{\text {rot }}-14.3\right.\right.$ e.u. $)+7.98$ e.u. $]$, where the last term is an empirical approximation of the change in the translational and rotational entropy of the molecule between the gas phase and the solution phase (due to the finite 
librational frequencies) derived from Wertz. ${ }^{27}$ For other species, the free energy was calculated as $G=E_{\text {gas }}+\Delta E_{\text {solv }}+\mathrm{ZPE}$ $+H_{\text {tot }}-T S+\Delta G_{\text {gas } \rightarrow \text { solv }}$, where $\Delta G_{\text {gas } \rightarrow \text { solv }}=k T \ln (24.5)$ represents the free energy change of compressing $1 \mathrm{~mol}$ of an ideal gas (volume $24.5 \mathrm{~L}$ at $25^{\circ} \mathrm{C}$ ) to $1 \mathrm{~L}$ (for $1 \mathrm{M}$ standard concentration). In the specific case of individual atoms or ions such as $\mathrm{H}_{\text {or }} \mathrm{Cl}^{-}, \mathrm{ZPE}=0$ and $H_{\text {tot }}=5 / 2 \mathrm{kT}$, and $\mathrm{S}$ is taken from Chase. $^{28}$

Some of the transition states calculated represent transitions between singlet and diradical states. For these complexes, we used the Yamaguchi broken symmetry method. ${ }^{29}$ First, the geometry and frequencies for the transition state were calculated using the same procedure as above with the overall system set as a triplet (i.e. the high spin case). Then, both the triplet and singlet single-point energies were calculated at this geometry, yielding electronic energies denoted $E^{\mathrm{HS}}$ and $E^{\mathrm{LS}}$, respectively. The actual electronic energy of the transition state was calculated using the formula $E=E^{\mathrm{LS}}-\beta\left(E^{\mathrm{HS}}-E^{\mathrm{LS}}\right)$ where $\beta=\left[\left\langle S^{2}\right\rangle^{\mathrm{LS}}-S^{\mathrm{LS}}\left(S^{\mathrm{LS}}+1\right)\right] /\left[\left\langle S^{2}\right\rangle^{\mathrm{HS}}-\left\langle S^{2}\right\rangle^{\mathrm{LS}}\right]$. Finally, the free energy was calculated from the electronic energy using the above equations.

\section{Treatment of acidity}

The hydration enthalpy and free energy of the proton have been determined to be $\Delta H_{\mathrm{aq}}{ }^{\circ}=-274.9 \mathrm{kcal} / \mathrm{mol}$ and $\Delta G_{\mathrm{aq}}{ }^{\circ}=-$ $264.0 \mathrm{kcal} / \mathrm{mol}$ from cluster-ion solvation data. ${ }^{30}$ This represents the energy change of a proton going from 1 atm gas to 1 $\mathrm{M}$ aqueous solution at $298.15 \mathrm{~K}$. We know that a gas-phase proton has zero electronic energy and so its enthalpy consists solely of the translational component: $H_{\mathrm{gas}}\left[\mathrm{H}^{+}\right]=5 / 2 \mathrm{kT}=1.5$ $\mathrm{kcal} / \mathrm{mol}$. We also know that the proton's entropy is purely translational, which we calculate to be $S\left[\mathrm{H}^{+}\right]=26.00$ e.u. using the formula $S=k \ln \left[\left(2 \pi \mathrm{m}_{\mathrm{p}} / h^{2}\right)^{3 / 2}(k T e)^{5 / 2}\right]{ }^{31}$ This leads to $G_{\text {gas }}\left[\mathrm{H}^{+}\right]=-6.3 \mathrm{kcal} / \mathrm{mol}$. The end results are $H_{\mathrm{aq}}\left[\mathrm{H}^{+}\right]=-273.4$ $\mathrm{kcal} / \mathrm{mol}$ and $G_{\mathrm{aq}}\left[\mathrm{H}^{+}\right]=-270.3 \mathrm{kcal} / \mathrm{mol}$. We use these numbers in our treatment of acidity.

\section{RESULTS}

We explored potential catalysts incorporating the $\kappa-\mathrm{P}$ phosphinite coordination to metal, i.e. with the (OPO) $\mathrm{V}^{\mathrm{V}}$ moiety. Although the inspiration for our proposed catalyst structure was heuristic in nature, our confidence in its predicted activity is bolstered by our comprehensive theoretical investigations of the system using density functional theory. In this section we discuss our results on various potential reactivity pathways.

One potential pitfall in the installation of the bis(2phenoxyl)phosphinite (OPO) ligand onto $\mathrm{V}$ would be the possibility that the $\mathrm{P}=\mathrm{O}$ moiety on the ligand might coordinate to the vanadium via the oxygen atom. However, at no time in our DFT geometry optimizations, aside from some high energy dianionic five-coordinate cases, did we observe this sort of isomerization, nor did we find negative curvatures in our calculated Hessian matrices. This implies that the homogeneous vanadium complex with a $\mathrm{V}-\mathrm{P}=\mathrm{O}$ unit is a stable coordination isomer that may be realistic to synthesis.

\section{Nomenclature}

Due to the number of complexes investigated, we propose a systematic shorthand naming convention. Since all of our complexes share the common motif of a vanadium atom bound $\kappa-\mathrm{P}$ to the $\mathrm{O}-\mathrm{P}(=\mathrm{O})-\mathrm{O}$ pincer ligand bis(2phenoxyl)phosphinite (OPO), we denote this commonality as (OPO)V. If there is an additional $\mathrm{R}$ group (such as a hydrogen atom) on the PO moiety of the (OPO), we label it as a subscript: $(\mathrm{OPO})_{\mathrm{R}} \mathrm{V}$. If the $\mathrm{V}$ atom is five-coordinate, then it adopts a trigonal bipyramidal geometry with the tridentate (OPO) occupying one axial and two equatorial coordination sites. This leaves two remaining coordination sites: the remaining equatorial site is labelled as $s$ since it is synperiplanar (syn) to the PO moiety of the bis(2-phenoxyl)phosphinite, and the remaining axial site is labelled as $a$ since it is axial and antiperiplanar (anti) to the same PO (Figure 3, left).

If the $\mathrm{V}$ atom is six-coordinate, then it adopts an octahedral geometry, and the (OPO) ligand may be in either a facial ( $f a c)$ or meridional (mer) configuration, denoted (OPO) ${ }^{f}$ and $(\mathrm{OPO})^{m}$, respectively (Figure 3 , center and right); leaving three remaining coordination sites. In the fac case, the three sites are labelled with the $c, s$, and $t$ superscripts, depending on whether they are clinal or syn to the PO moiety of the (OPO) $)^{f}$, or trans to the $\mathrm{P}$, respectively. In the mer case, the three coordination sites are labelled with the $s, t$, or $a$ superscripts, depending on whether they are syn to the PO, trans to the P, or anti to the PO, respectively. Under this system, the three conformational species shown in Figure 3 can be unambiguously expressed as

- $(\mathrm{OPO})_{\mathrm{R}} \mathrm{V}\left(\mathrm{L}_{1}\right)^{s}\left(\mathrm{~L}_{2}\right)^{a}: \mathrm{V}$ is 5-coordinate, $\mathrm{R}$ attached to PO, $\mathrm{L}_{1}$ syn to $\mathrm{PO}, \mathrm{L}_{2}$ anti to $\mathrm{PO}$;

- $(\mathrm{OPO})_{\mathrm{R}}^{f} \mathrm{~V}\left(\mathrm{~L}_{1}\right)^{c}\left(\mathrm{~L}_{2}\right)^{s}\left(\mathrm{~L}_{3}\right)^{t}: \mathrm{V}$ is 6-coordinate, $(\mathrm{OPO})$ is facial with $\mathrm{R}$ attached to $\mathrm{PO}, \mathrm{L}_{1}$ clinal to $\mathrm{PO}, \mathrm{L}_{2}$ syn to $\mathrm{PO}$, and $\mathrm{L}_{3}$ trans to $\mathrm{P}$; and

- $(\mathrm{OPO})^{m}{ }_{\mathrm{R}} \mathrm{V}\left(\mathrm{L}_{1}\right)^{s}\left(\mathrm{~L}_{2}\right)^{t}\left(\mathrm{~L}_{3}\right)^{a}: \mathrm{V}$ is 6-coordinate, (OPO) is meridional with $\mathrm{R}$ attached to $\mathrm{PO}, \mathrm{L}_{1}$ syn to $\mathrm{PO}, \mathrm{L}_{2}$ trans to $\mathrm{P}$, and $\mathrm{L}_{3}$ anti to $\mathrm{PO}$.

Note that in some fac cases, the PO moiety is twisted enough such that the clinal and syn positions on the $\mathrm{V}$ both become gauche. Since this phenomenon was not universal, no relabeling of clinal and syn markers was done.
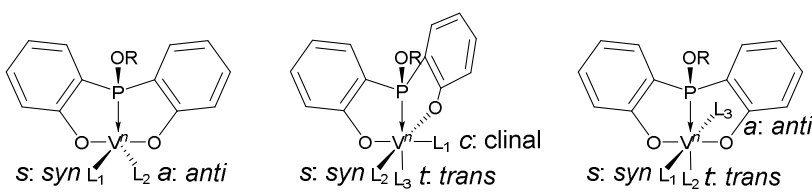

$(\mathrm{OPO})_{\mathrm{R}} \mathrm{V}^{n}\left(\mathrm{~L}_{1}\right)^{s}\left(\mathrm{~L}_{2}\right)^{a}$

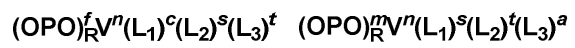

Figure 3. Template for the nomenclature of investigated complexes. For the (OPO) ligand, an $f$ superscript denotes that the chelation is facial whereas an $m$ superscript denotes that it is meridional. For the $\mathrm{V}$ atom, $n$ is the oxidation state. For the ligands $\mathrm{L}_{n}$, the superscript $a$ denotes that the ligand is anti to the PO moiety; $s$ denotes that it is syn to the PO moiety; $c$ denotes that it is clinal to the PO moiety; and $t$ denotes that it is trans to the $\mathrm{P}$ atom.

\section{The resting $V^{\mathrm{V}}$ state}

The first consideration to be investigated is the precise nature of the resting $\mathrm{V}^{\mathrm{V}}$ state: whether it is five or six coordinate, charged or uncharged, with the (OPO) ligand in a fac or mer conformation, and with what optimal combination of oxo, hydroxo, and aqua ligands. The $\mathrm{pH}$ of the environments investigated was set to 0 in order to simplify the calculation of 
standard free energies (all species $1 \mathrm{M}$ ). Changing the ambient $\mathrm{pH}$ does not affect the relative energetics of isomeric species with the same charge, but does change which charge cohort of species will be most stable.

Our prior communication focused on the complex $(\mathrm{OPO}) \mathrm{V}^{\mathrm{V}} \mathrm{Cl}_{2}(\mathbf{1})$; however, in aqueous solution we expect the chlorides to be hydrolyzed and replaced with hydroxo/aqua ligands and at least one strong vanadium oxo bond. ${ }^{8 \mathrm{~b}}$ Table S1 provides a comprehensive compilation of all $(\mathrm{OPO}) \mathrm{V}^{\mathrm{V}}=\mathrm{O}$ species studied. in fast equilibrium. Indeed, hydrolysis of the chlorides in $(\mathrm{OPO}) \mathrm{V}^{\mathrm{V}} \mathrm{Cl}_{2}$ to form $(\mathrm{OPO}) \mathrm{V}^{\mathrm{V}}(\mathrm{OH})_{2}$ (2) is only slightly downhill, but conversion of $\mathbf{2}$ to $\mathbf{4}$ is much more favorable (Scheme 2).

- The lowest energy 6-coordinate fac isomer is $(\mathrm{OPO})_{\mathrm{H}}^{f} \mathrm{~V}^{\mathrm{V}} \mathrm{O}^{c}(\mathrm{OH})^{s}\left(\mathrm{H}_{2} \mathrm{O}\right)^{t}(\mathbf{1 6})$, which is $14.0 \mathrm{kcal} / \mathrm{mol}$ higher in energy;

- the lowest energy 6-coordinate mer isomer is $(\mathrm{OPO})^{m} \mathrm{~V}^{\mathrm{V}} \mathrm{O}^{s}\left(\mathrm{H}_{2} \mathrm{O}\right)_{2}{ }^{t a}(\mathbf{4 0})$, which is $18.0 \mathrm{kcal} / \mathrm{mol}$ higher in energy.

The most stable species are the neutral five-coordinate $(\mathrm{OPO}) \mathrm{V}^{\mathrm{V}} \mathrm{O}^{s}\left(\mathrm{H}_{2} \mathrm{O}\right)^{a}(\mathbf{4})$ and $(\mathrm{OPO})_{\mathrm{H}} \mathrm{V}^{\mathrm{V}} \mathrm{O}^{s}(\mathrm{OH})^{a}(\mathbf{6})$, which exist

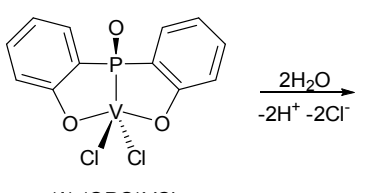

(1) (OPO) $\mathrm{VCl}_{2}$

$\Delta \mathrm{G}_{\mathrm{rel}}=11.4$

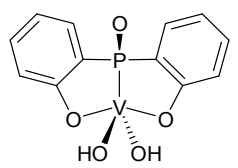

(2) $(\mathrm{OPO}) \mathrm{V}(\mathrm{OH})$

$\Delta \mathrm{G}_{\mathrm{rel}}=9.4$
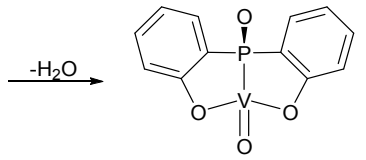

(3) $(\mathrm{OPO}) \mathrm{V}=\mathrm{O}$

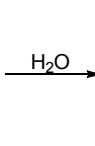

$\Delta \mathrm{G}_{\mathrm{rel}}=2.4$

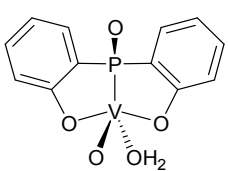

(4) $(\mathrm{OPO}) \mathrm{VO}^{\mathrm{s}}\left(\mathrm{H}_{2} \mathrm{O}\right)^{\mathrm{a}}$

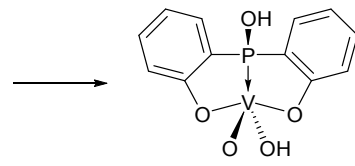

(6) $(\mathrm{OPO})_{\mathrm{H}} \mathrm{VO}^{\mathrm{s}}(\mathrm{OH})^{\mathrm{a}}$ $\Delta \mathrm{G}_{\mathrm{rel}}=0.0$

Scheme 2. Our original complex $(\mathrm{OPO}) \mathrm{V}^{\mathrm{V}} \mathrm{Cl}_{2}(1)$ is hydrolyzed in water to $(\mathrm{OPO})_{\mathrm{H}} \mathrm{V}^{\mathrm{V}} \mathrm{O}^{s}(\mathrm{OH})^{a}(6)$. This 5-coordinate species is the lowest energy isomer in aqueous solution. All $\Delta G_{\text {rel }}$ values are relative to 6 and in kcal/mol.

\section{Activation of propane substrate}

Propane has both primary and secondary $\mathrm{C}-\mathrm{H}$ bonds, with the secondary $\mathrm{C}-\mathrm{H}$ bond in the middle carbon more easily activated due to the increased stability of the resulting secondary radical. Those $(\mathrm{OPO}) \mathrm{V}^{\mathrm{V}}$ species that contain unadorned intact $\mathrm{P}=\mathrm{O}$ moieties are listed in Table $\mathrm{S} 1$. These were further investigated for their ability to activate the secondary $\mathrm{C}-\mathrm{H}$ bond of propane. The transition states were located and their free energies were calculated relative to the resting state $(\mathrm{OPO})_{\mathrm{H}} \mathrm{V}^{\mathrm{V}} \mathrm{O}^{s}(\mathrm{OH})^{a}(\mathbf{6})$. The results are shown in Table $\mathrm{S} 2$.

According to Table S2, the lowest-energy transition state is the five-coordinate neutral species $\left[(\mathrm{OPO})_{\mathrm{HiPr}} \mathrm{VO}^{s}\left(\mathrm{H}_{2} \mathrm{O}\right)^{a}\right]^{*}(67)$, which is $24.6 \mathrm{kcal} / \mathrm{mol}$ higher in free energy than the precursor $(\mathrm{OPO}) \mathrm{V}^{\mathrm{V}} \mathrm{O}^{s}\left(\mathrm{H}_{2} \mathrm{O}\right)^{a}$ (4) $+\mathrm{HiPr}$. Its structure is shown in Scheme 3 . We consider this to be accessible for $\mathrm{C}-\mathrm{H}$ activation, with an overall barrier of $\Delta G^{\ddagger}=25.2 \mathrm{kcal} / \mathrm{mol}$. Analysis of the Mulliken spin density supports our assignment of radical character: Although the overall spin is 0 , we find spin densities of

- 1.06 on the vanadium,

- -0.47 on the propane secondary carbon,

- -0.25 on the attacking PO oxygen,

- $\quad-0.11$ on the vanadium oxo, but only

- -0.04 on the $\mathrm{P}$,

supporting our assertion of attack via the ROA mechanism.

The $\mathrm{C}-\mathrm{H}$ activation transition state has an isopropyl radical and a monohydrogenated $(\mathrm{OPO})_{\mathrm{H}} \mathrm{V}^{\mathrm{IV}}$ complex, which may then isomerize into other $(\mathrm{OPO}) \mathrm{V}^{\mathrm{IV}}$ species. The various $(\mathrm{OPO}) \mathrm{V}^{\mathrm{IV}}$ complexes are listed in Table S3. Only fivecoordinate and six-coordinate fac-(OPO) complexes were exhaustively investigated, since our results show consistently that they are lower in energy than their six-coordinate mer counterparts. The lowest energy species is $(\mathrm{OPO})_{\mathrm{H}} \mathrm{V}^{\mathrm{IV}} \mathrm{O}^{s}\left(\mathrm{H}_{2} \mathrm{O}\right)^{a}(\mathbf{1 0 2})$. All $(\mathrm{OPO}) \mathrm{V}^{\mathrm{IV}}$ species are doublets, and Mulliken spin density analysis reveals that the spins are localized on the vanadium atoms, supporting the assignment of vanadium in the +IV oxidation state. The initial propane activation step from $\mathbf{4}$ to $\mathbf{1 0 2}$ is shown in Scheme 3 along with their structures.

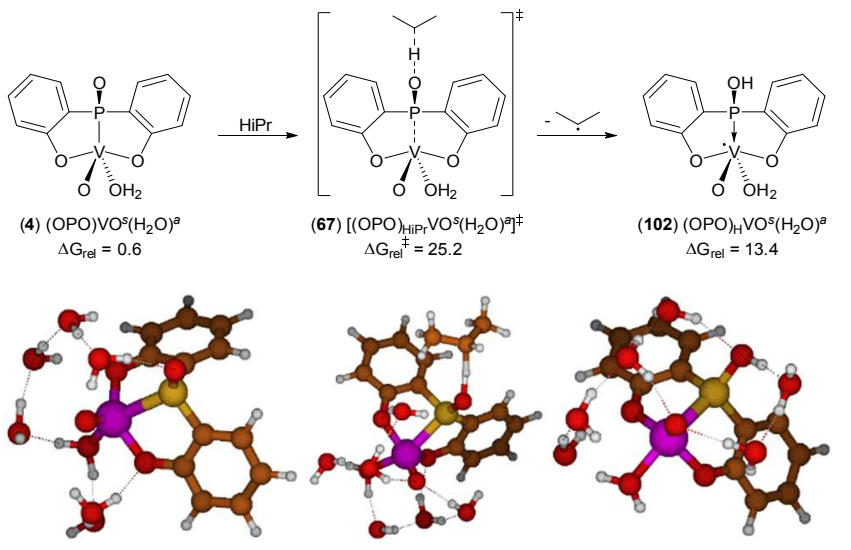

Scheme 3. One of the lowest energy $V^{V}$ species, $(\mathrm{OPO}) \mathrm{V}^{\mathrm{V}} \mathrm{O}^{s}\left(\mathrm{H}_{2} \mathrm{O}\right)^{a}(4)$, is able to activate the isopropyl hydrogen with $\Delta G^{\ddagger}=24.6 \mathrm{kcal} / \mathrm{mol}$ via $\left[(\mathrm{OPO})_{\mathrm{HiPr}} \mathrm{VO}^{s}\left(\mathrm{H}_{2} \mathrm{O}\right)^{a}\right]^{\ddagger}(67)$. The result is the lowest energy $\mathrm{V}^{\mathrm{IV}}$ species, $(\mathrm{OPO})_{\mathrm{H}} \mathrm{V}^{\mathrm{IV}} \mathrm{O}^{s}\left(\mathrm{H}_{2} \mathrm{O}\right)^{a}(102)$. The geometry optimized structures of each species is shown beneath the corresponding drawing. All $\Delta G_{\text {rel }}$ values are relative to 6 and in $\mathrm{kcal} / \mathrm{mol}$.

Since reactive isopropyl radicals are generated upon $\mathrm{H}$-atom abstraction, it is most likely that they are immediately trapped by the (OPO) $\mathrm{V}^{\mathrm{IV}}$ intermediate. Taking inspiration from Cheng and Goddard, ${ }^{4}$ who found that the produced isopropyl radical is adsorbed onto a $\mathrm{V}=\mathrm{O}$ moiety, we considered the possibility that the isopropyl radical rebounds onto the monohydrogenated species $(\mathrm{OPO})_{\mathrm{H}} \mathrm{V}^{\mathrm{IV}} \mathrm{O}^{s}\left(\mathrm{H}_{2} \mathrm{O}\right)^{a} \quad(\mathbf{1 0 2})$ to form an $(\mathrm{OPO}) \mathrm{V}^{\mathrm{III}}(\mathrm{OiPr})$ species. The isopropoxy ligand may then be protonated and exchanged with an aqua ligand, producing isopropanol.

Table $\mathrm{S} 4$ is a comprehensive list of $(\mathrm{OPO}) \mathrm{V}^{\mathrm{III}}(\mathrm{OiPr})$ species with neutral or -1 charge. Unlike the case of the $\mathrm{V}^{\mathrm{V}}$ and $\mathrm{V}^{\mathrm{IV}}$ species, the most stable (OPO) $\mathrm{V}^{\mathrm{III}}(\mathrm{OiPr})$ species is a sixcoordinate complex with the (OPO) ligand in the fac configu- 
ration, ${ }^{3}\left[(\mathrm{OPO})^{f} \mathrm{~V}^{\mathrm{III}}(\mathrm{HOiPr})^{s}\left(\mathrm{H}_{2} \mathrm{O}\right)_{2}{ }^{c t}\right]$ (168). Furthermore, the triplet states are universally more stable than their singlet counterparts, supporting the +III assignment for the oxidation state of the vanadium atom. As a result, only five-coordinate and triplet six-coordinate $f a c-(\mathrm{OPO})$ complexes were investigated exhaustively.

From the energies in Table S4, we see that it is energetically exergonic by $30.9 \mathrm{kcal} / \mathrm{mol}$ for the isopropyl radical to rebound onto the monohydrogenated species $(\mathrm{OPO})_{\mathrm{H}} \mathrm{V}^{\mathrm{IV}} \mathrm{O}^{s}\left(\mathrm{H}_{2} \mathrm{O}\right)^{a}(\mathbf{1 0 2})$ to form the five-coordinate species ${ }^{3}\left[(\mathrm{OPO})_{\mathrm{H}} \mathrm{V}^{\mathrm{III}}(\mathrm{OiPr})^{s}\left(\mathrm{H}_{2} \mathrm{O}\right)^{a}\right]$ (148). It is slightly uphill by 1.4 $\mathrm{kcal} / \mathrm{mol}$ for $\mathbf{1 4 8}$ to add on an additional aqua ligand to form ${ }^{3}\left[(\mathrm{OPO})_{\mathrm{H}}^{f} \mathrm{~V}^{\mathrm{III}}(\mathrm{OiPr})^{s}\left(\mathrm{H}_{2} \mathrm{O}\right)_{2}{ }^{c t}\right](\mathbf{1 7 7})$. Finally, it is favorable by $2.7 \mathrm{kcal} / \mathrm{mol}$ for $\mathbf{1 7 7}$ to isomerize to the lowest energy 6coordinate isomer, ${ }^{3}\left[(\mathrm{OPO})^{f} \mathrm{~V}^{\mathrm{III}}(\mathrm{HOiPr})^{s}\left(\mathrm{H}_{2} \mathrm{O}\right)_{2}{ }^{c t}\right]$ (168). The isopropyl rebound step from $\mathbf{1 0 2}$ to $\mathbf{1 6 8}$ is shown in Scheme 4 along with their structures. Transition state energies were assumed to be small and not calculated.

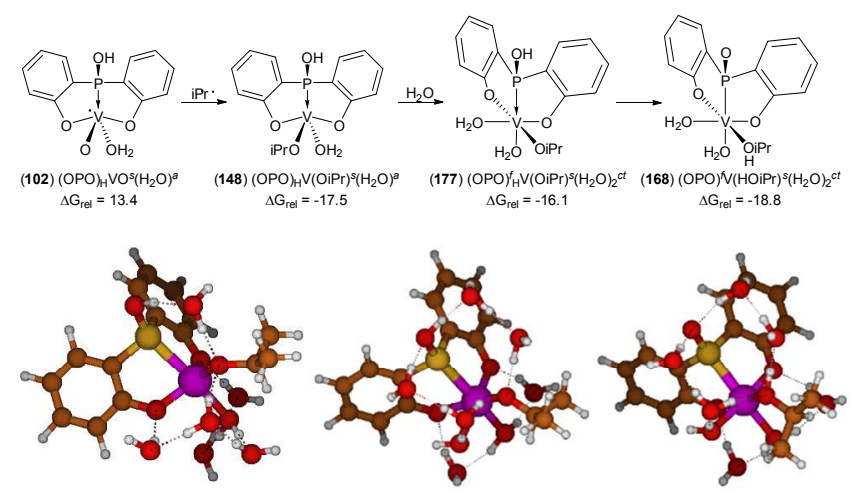

Scheme 4. The lowest energy $V^{\mathrm{IV}}$ species, $(\mathrm{OPO})_{\mathrm{H}} \mathrm{V}^{\mathrm{IV}} \mathrm{O}^{s}\left(\mathrm{H}_{2} \mathrm{O}\right)^{a}(102)$, rebounds with isopropyl radical to form ${ }^{3}\left[(\mathrm{OPO})_{\mathrm{H}} \mathrm{V}^{\mathrm{III}}(\mathrm{OiPr})^{s}\left(\mathrm{H}_{2} \mathrm{O}\right)^{a}\right] \quad(148)$. This fivecoordinate species adds an aqua ligand and isomerizes to ${ }^{3}\left[(\mathrm{OPO})^{f} \mathbf{V}^{\mathrm{III}}(\mathrm{HOiPr})^{s}\left(\mathrm{H}_{2} \mathrm{O}\right)_{2}{ }^{c t}\right] \quad(168)$, the lowest energy (OPO)V ${ }^{\mathrm{III}}$ (OiPr) species. The geometry optimized structures of 148, 177, and 168 are shown below the scheme. All $V^{\mathrm{III}}$ species shown are triplets and all $\Delta G_{\text {rel }}$ values are relative to 6 and in $\mathrm{kcal} / \mathrm{mol}$.

\section{Release of isopropanol product and reaction with dioxygen}

In order to complete the catalytic cycle, the $(\mathrm{OPO}) \mathrm{V}^{\mathrm{III}}(\mathrm{OiPr})$ species such as ${ }^{3}\left[(\mathrm{OPO})^{f} \mathrm{~V}^{\mathrm{III}}(\mathrm{HOiPr})^{s}\left(\mathrm{H}_{2} \mathrm{O}\right)_{2}{ }^{c t}\right](\mathbf{1 6 8})$ must both release the isopropanol product and undergo reoxidation back to $\mathrm{V}^{\mathrm{V}}$. Naturally, we are most interested in the possibility of
$\mathrm{O}_{2}$ being the oxidant. We expect dioxygen to bind to the $\mathrm{V}^{\mathrm{III}}$ species to form $\mathrm{V}^{\mathrm{V}}$-peroxides. Hence, we explored two possibilities:

- $\quad$ in the first, 168 first loses iPrOH to form a (OPO) $V^{I I I}$ species with only aqua/hydroxo/oxo ligands, which then adds $\mathrm{O}_{2}$ to form a (OPO) $\mathrm{V}^{\mathrm{V}}\left(\mathrm{O}_{2}\right)$ peroxide; and

- in the second, $\mathbf{1 6 8}$ first adds $\mathrm{O}_{2}$ to form a $(\mathrm{OPO}) \mathrm{V}^{\mathrm{V}}(\mathrm{OiPr})\left(\mathrm{O}_{2}\right)$ peroxide, and then loses iPrOH.

Either way, the result is the formation of a $(\mathrm{OPO}) \mathrm{V}^{\mathrm{V}}\left(\mathrm{O}_{2}\right)$ peroxide.

Table S5 shows the (OPO) $\mathrm{V}^{\mathrm{III}}$ species investigated. Loss of isopropanol from $\mathbf{1 6 8}$ results in the formation of ${ }^{3}\left[(\mathrm{OPO}) \mathrm{V}^{\mathrm{III}}\left(\mathrm{H}_{2} \mathrm{O}\right){ }_{2}{ }^{s a}\right] \quad(\mathbf{1 9 8})$; however, the lowest fivecoordinate species ${ }^{3}\left[(\mathrm{OPO})_{\mathrm{H}} \mathrm{V}^{\mathrm{III}}(\mathrm{OH})^{s}\left(\mathrm{H}_{2} \mathrm{O}\right)^{a}\right]$ (200) is 5.4 $\mathrm{kcal} / \mathrm{mol}$ lower in energy, and the lowest six-coordinate species ${ }^{3}\left[(\mathrm{OPO})^{f} \mathrm{~V}^{\mathrm{III}}\left(\mathrm{H}_{2} \mathrm{O}\right)_{3}{ }^{\text {cst }}\right](\mathbf{2 1 0})$ is $1.0 \mathrm{kcal} / \mathrm{mol}$ higher in energy. As with the (OPO) $\mathrm{V}^{\mathrm{III}}(\mathrm{OiPr})$ case, the triplet is universally lower in energy than the singlet, as expected.

Table S6 shows the $(\mathrm{OPO}) \mathrm{V}^{\mathrm{V}}(\mathrm{OiPr})\left(\mathrm{O}_{2}\right)$ peroxide species investigated. As with the $(\mathrm{OPO}) \mathrm{V}^{\mathrm{III}}(\mathrm{OiPr})$ case, the 6-coordinate species is preferred with $(\mathrm{OPO})^{f} \mathrm{~V}^{\mathrm{V}}(\mathrm{HOiPr})^{t}\left(\eta^{2}-\mathrm{O}_{2}\right)^{s}\left(\mathrm{H}_{2} \mathrm{O}\right)^{c}$ (278) as the lowest energy species.

Table $\mathrm{S} 7$ shows the $(\mathrm{OPO}) \mathrm{V}^{\mathrm{V}}\left(\mathrm{O}_{2}\right)$ peroxide species investigated. The lowest five-coordinate species, (OPO) $\mathrm{V}^{\mathrm{V}}\left(\eta^{2}-\right.$ $\left.\mathrm{O}_{2}\right)^{s}\left(\mathrm{H}_{2} \mathrm{O}\right)^{a}(\mathbf{3 8 1})$, is $4.9 \mathrm{kcal} / \mathrm{mol}$ lower in energy than the lowest six-coordinate species, $(\mathrm{OPO})^{f} \mathrm{~V}^{\mathrm{V}}\left(\eta^{2}-\mathrm{O}_{2}\right)^{c}\left(\mathrm{H}_{2} \mathrm{O}\right)_{2}{ }^{s t}(\mathbf{4 0 9})$.

Scheme 5 shows the two pathways studied from ${ }^{3}\left[(\mathrm{OPO})^{f} \mathrm{~V}^{\mathrm{III}}(\mathrm{HOiPr})^{s}\left(\mathrm{H}_{2} \mathrm{O}\right)_{2}{ }^{c t}\right](\mathbf{1 6 8})$ to $(\mathrm{OPO}) \mathrm{V}^{\mathrm{V}}\left(\mathrm{O}_{2}\right)$ peroxide species, the top being oxidation to $(\mathrm{OPO})^{f} \mathrm{~V}^{\mathrm{V}}(\mathrm{HOiPr})^{t}\left(\eta^{2}-\right.$ $\left.\mathrm{O}_{2}\right)^{s}\left(\mathrm{H}_{2} \mathrm{O}\right)^{c}$ (278) followed by iPrOH loss to 381, and the bottom being iPrOH loss to ${ }^{3}\left[(\mathrm{OPO}) \mathrm{V}^{\mathrm{III}}\left(\mathrm{H}_{2} \mathrm{O}\right)_{2}{ }^{\text {sa }}\right]$ (198) followed by oxidation to 409 . We see from Scheme 5 that the oxidationfirst pathway through 140 and $\mathbf{2 7 8}$ (top) goes through lower energy intermediates than the bottom pathway through 198 and 409 (Compare $\Delta G_{\text {rel }}=-12.9$ for 140 versus -10.9 for 198).

Hence, we conclude that the top pathway is more likely, i.e. the $(\mathrm{OPO}) \mathrm{V}^{\mathrm{III}}(\mathrm{OiPr})$ species 168 must be first oxidized to $\mathrm{V}^{\mathrm{V}}$ before HOiPr may be released. Compared to our prior results with vanadium oxide clusters, we see in this case that aqua and alcohol ligands can be labilized before oxidation from + III to $+\mathrm{V}$ due to the higher coordination of the vanadium centre. ${ }^{32}$ 


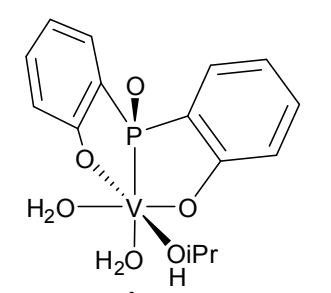

(168) $(\mathrm{OPO})^{f} \mathrm{~V}(\mathrm{HOiPr})^{s}\left(\mathrm{H}_{2} \mathrm{O}\right)_{2}{ }^{c t}$ $\Delta \mathrm{G}_{\mathrm{rel}}=-18.8$<smiles>O[P+]1(O)Oc2ccccc2P1(O)(O)O</smiles>

(200) $(\mathrm{OPO})_{\mathrm{H}} \mathrm{V}(\mathrm{OH})^{\mathrm{s}}\left(\mathrm{H}_{2} \mathrm{O}\right)^{a}$ $\Delta \mathrm{G}_{\mathrm{rel}}=-16.3$

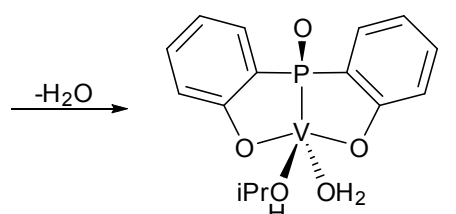

(140) $(\mathrm{OPO}) \mathrm{V}(\mathrm{HOiPr})^{s}\left(\mathrm{H}_{2} \mathrm{O}\right)^{a}$ $\Delta \mathrm{G}_{\mathrm{rel}}=-12.9$
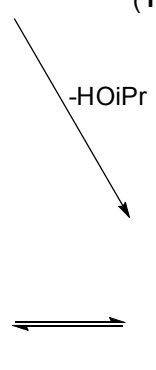

4

(198) $(\mathrm{OPO}) \mathrm{V}\left(\mathrm{H}_{2} \mathrm{O}\right)_{2}{ }^{\mathrm{sa}}$ $\Delta \mathrm{G}_{\text {rel }}=-10.9$

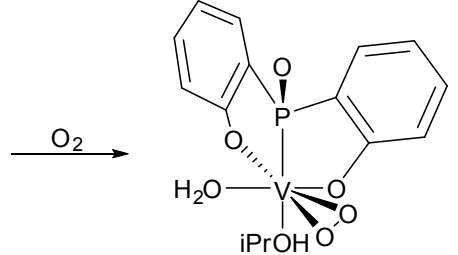

(278) $(\mathrm{OPO})^{f} \mathrm{~V}(\mathrm{HOiPr})^{t}\left(\mathrm{O}_{2}\right)^{s}\left(\mathrm{H}_{2} \mathrm{O}\right)^{c}$ $\Delta \mathrm{G}_{\mathrm{rel}}=-19.7$
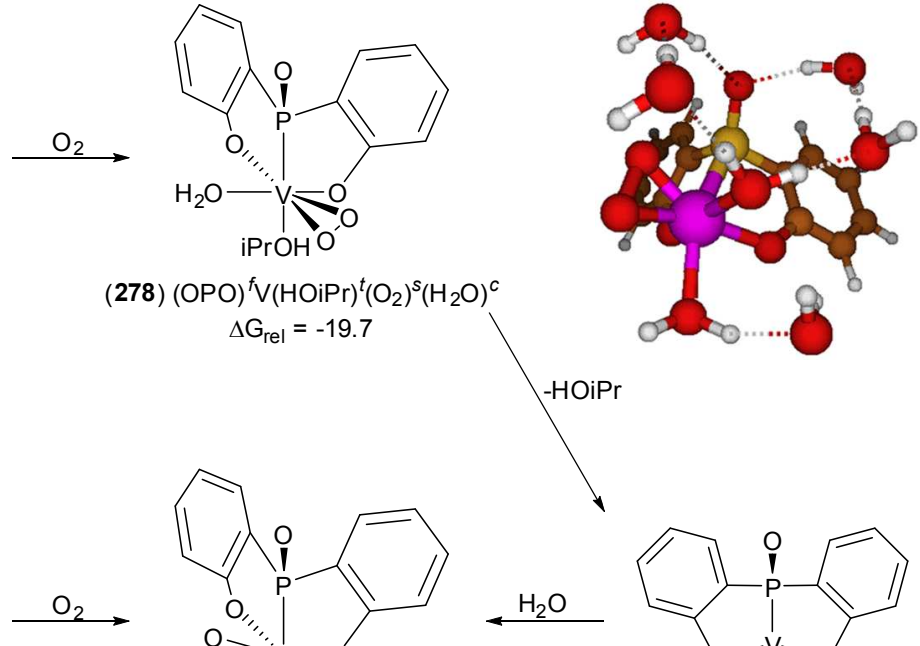

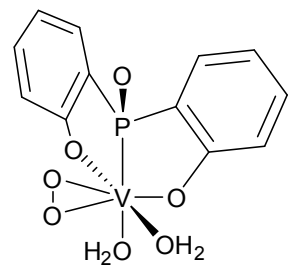

(409) $(\mathrm{OPO})^{f} \mathrm{~V}\left(\mathrm{O}_{2}\right)^{c}\left(\mathrm{H}_{2} \mathrm{O}\right)_{2}^{\text {st }}$ $\Delta \mathrm{G}_{\mathrm{rel}}=-21.1$

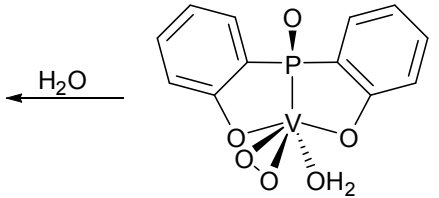

(381) (OPO) $\left(\mathrm{O}_{2}\right)^{s}\left(\mathrm{H}_{2} \mathrm{O}\right)^{a}$ $\Delta \mathrm{G}_{\mathrm{rel}}=-16.2$

Scheme 5. The lowest energy $(\mathrm{OPO}) \mathrm{V}^{\mathrm{III}}(\mathrm{OiPr})$ species, $(\mathrm{OPO})^{f} \mathrm{~V}^{\mathrm{III}}(\mathrm{HOiPr})^{s}\left(\mathrm{H}_{2} \mathrm{O}\right)_{2}{ }^{c t}(168)$, releases isopropanol and adds an oxygen molecule to form a (OPO) $\mathrm{V}^{\mathrm{V}}\left(\mathrm{O}_{2}\right)$ peroxide species $(381$ or 409$)$. It can either add oxygen first (top pathway, through 278), or lose the isopropanol first (bottom pathway, through 198). The geometry optimized structure of 409 is shown in the top right corner of the scheme. All $V^{\text {III }}$ species shown are triplets and all $\Delta G_{\text {rel }}$ values are relative to 6 and in $\mathrm{kcal} / \mathrm{mol}$.

\section{Transformation back to the resting state species}

The final step is the transformation of the peroxide $(\mathrm{OPO})^{f} \mathrm{~V}^{\mathrm{V}}\left(\eta^{2}-\mathrm{O}_{2}\right)^{c}\left(\mathrm{H}_{2} \mathrm{O}\right)_{2}{ }^{\text {st }}(\mathbf{4 0 9})$ back to the resting state species, $(\mathrm{OPO})_{\mathrm{H}} \mathrm{V}^{\mathrm{V}} \mathrm{O}^{s}\left(\mathrm{H}_{2} \mathrm{O}\right)^{a}(\mathbf{6})$. We considered two possibilities as to how this may occur: through the formation of a dimeric $\mathrm{V}_{2} \mathrm{O}_{2}$ species, and through the protonation of the peroxide to form $\mathrm{H}_{2} \mathrm{O}_{2}$. We believe the latter route is more likely under catalytic concentrations (see Discussion).

The first potential mechanism is that $\mathbf{4 0 9}$ reacts with another equivalent of $(\mathrm{OPO}) \mathrm{V}^{\mathrm{III}}$, for instance ${ }^{3}\left[(\mathrm{OPO}) \mathrm{V}^{\mathrm{III}}\left(\mathrm{H}_{2} \mathrm{O}\right)_{2}{ }^{s a}\right]$ (198), forming a dimeric species with a $\mathrm{V}^{\mathrm{IV}}-\mathrm{O}-\mathrm{O}-\mathrm{V}^{\mathrm{IV}}$ peroxide bridge than can quickly homolyze to two $(\mathrm{OPO}) \mathrm{V}^{\mathrm{V}}$ species.

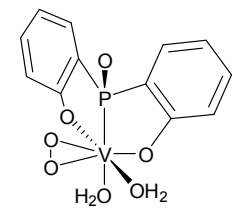

(409) $(\mathrm{OPO})^{t} \mathrm{~V}\left(\mathrm{O}_{2}\right)^{c}\left(\mathrm{H}_{2} \mathrm{O}\right)_{2}^{\text {st }}$ $\Delta \mathrm{G}_{\mathrm{rel}}=-21.1$

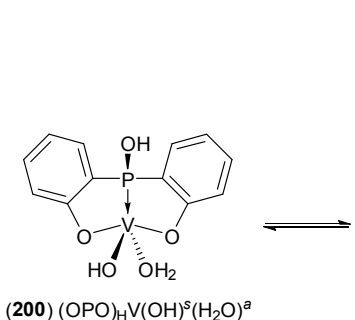

(200) $(\mathrm{OPO})_{\mathrm{H}} \mathrm{V}(\mathrm{OH})^{s}\left(\mathrm{H}_{2} \mathrm{O}\right)^{a}$ $\Delta \mathrm{G}_{\mathrm{rel}}=-16.3$

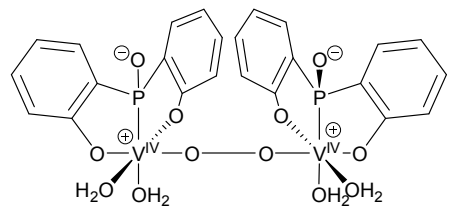

(458) $(\mathrm{OPO})^{f} \mathrm{~V}\left(\mathrm{H}_{2} \mathrm{O}\right)_{2}{ }^{c t-} \mathrm{O}^{s}-\mathrm{O}^{c}-\left(\mathrm{H}_{2} \mathrm{O}\right)_{2}{ }^{s t} \mathrm{~V}(\mathrm{OPO})^{f}$ $\Delta \mathrm{G}_{\mathrm{rel}}=-37.2(-21.1-10.9-5.2)$

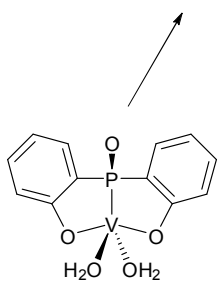

(198) $(\mathrm{OPO}) \mathrm{V}\left(\mathrm{H}_{2} \mathrm{O}\right)_{2}{ }^{\mathrm{sa}}$ $\Delta \mathrm{G}_{\mathrm{rel}}=-10.9$

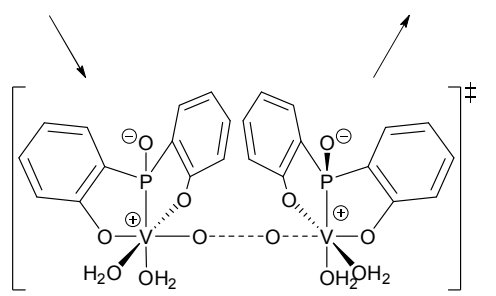

(457) $\left[(\mathrm{OPO})^{f} \mathrm{~V}\left(\mathrm{H}_{2} \mathrm{O}\right)_{2}{ }^{c t}-\mathrm{O}^{s}-\mathrm{O}^{c}-\left(\mathrm{H}_{2} \mathrm{O}\right)_{2}{ }^{s t} \mathrm{~V}(\mathrm{OPO})^{f t}\right]^{\ddagger}$ $\Delta G_{\text {rel }}^{\ddagger}=-24.8$
The dimeric transition state we found is ${ }^{1}\left\{\left[(\mathrm{OPO})^{f} \mathrm{~V}\left(\mathrm{H}_{2} \mathrm{O}\right)_{2}{ }^{\text {st }}\right.\right.$ $\left.\left.\mathrm{O}^{c}\right]-\left[\mathrm{O}^{s}-\left(\mathrm{H}_{2} \mathrm{O}\right)_{2}{ }^{c t} \mathrm{~V}(\mathrm{OPO})^{f}\right]\right\}^{\ddagger}(\mathbf{4 5 7})$, with a large negative frequency corresponding to vibration along the $\mathrm{V}-\mathrm{O}-\mathrm{O}-\mathrm{V}$ peroxide bridge. Minimizing the geometry of this species as a triplet leads to the dimeric intermediate ${ }^{3}\left\{\left[(\mathrm{OPO})^{\mathrm{f}} \mathrm{V}^{\mathrm{IV}}\left(\mathrm{H}_{2} \mathrm{O}\right)_{2}{ }^{\text {st }}-\mathrm{O}^{c}\right]-\right.$ $\left.\left[\mathrm{O}^{s}-\left(\mathrm{H}_{2} \mathrm{O}\right)_{2}{ }^{c t} \mathrm{~V}^{\mathrm{IV}}(\mathrm{OPO})^{f}\right]\right\}(\mathbf{4 5 8})$, while minimizing as a singlet leads to a hydrogen-bonded complex of $(\mathrm{OPO})^{f} \mathrm{~V}^{\mathrm{V}} \mathrm{O}^{c}\left(\mathrm{H}_{2} \mathrm{O}\right)_{2}{ }^{s t}$ (13) and $(\mathrm{OPO})^{f} \mathrm{~V}^{\mathrm{V}} \mathrm{O}^{c}\left(\mathrm{H}_{2} \mathrm{O}\right)_{2}{ }^{\text {st }}(\mathbf{1 4})$. Both 13 and 14 may then lose aqua ligands to reform the starting 5-coordinate species $\mathbf{6}$. The process is shown in Scheme 6, leading to an overall barrier of $12.4 \mathrm{kcal} / \mathrm{mol}$. Details on the energetics of $\mathbf{4 5 7 - 4 5 8}$ are listed in Table S8. Although there may be other dimeric transition state species with lower energies, we can see that the process is facile and $12.4 \mathrm{kcal} / \mathrm{mol}$ is at the very least an upper bound on the barrier.

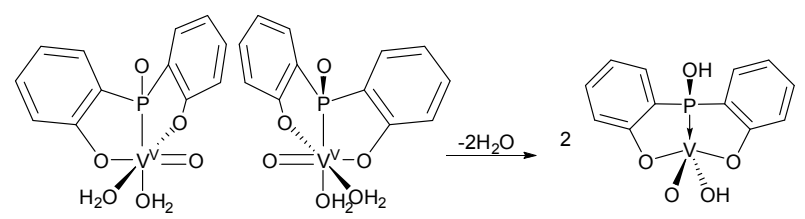

$$
(14)+(13) \quad 2 \times(6)(\mathrm{OPO})_{\mathrm{H}} \mathrm{VO}^{s}(\mathrm{OH})^{\mathrm{a}}
$$$$
\Delta \mathrm{G}_{\mathrm{rel}}=-48.3(-22.6-25.7)
$$
$\Delta \mathrm{G}_{\mathrm{rel}}=-82.9(2 \mathrm{x}-41.4)$

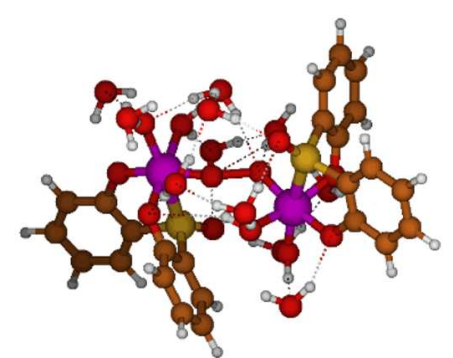

Scheme 6. Reforming the starting species 6 from the $(O P O)^{f} V^{\mathrm{V}}$ peroxide 409 and the (OPO) $\mathrm{V}^{\mathrm{III}} 198$. Note that $\Delta G_{\text {rel }}$ for 458 is calculated from the sum of $\Delta G_{\text {rel }}$ 's for 409 and 198 plus the $-5.2 \mathrm{kcal} / \mathrm{mol}$ free energy change of the reaction $409+198 \rightarrow$ 
458. Also note that 6 in this scheme is at -82.9 because $\Delta G=-82.9 \mathrm{kcal} / \mathrm{mol}$ for the reaction $2 \mathrm{iPrH}+\mathrm{O}_{2} \rightarrow 2 \mathrm{iPrOH}$. $\mathrm{The}$ geometry optimized structure of 457 is shown in the bottom right corner of the scheme. All $\Delta G_{\text {rel }}$ values are in $\mathrm{kcal} / \mathrm{mol}$ and $\begin{array}{llllllll}\text { relative to } & 6 & \text { at } & \text { the } & \text { beginning } & \text { of } & \text { the action. }\end{array}$

The second possibility is that a $(\mathrm{OPO}) \mathrm{V}^{\mathrm{V}}\left(\mathrm{O}_{2}\right)$ peroxide species, such as $(\mathrm{OPO})^{f} \mathrm{~V}^{\mathrm{V}}(\mathrm{HOiPr})^{t}\left(\mathrm{O}_{2}\right)^{s}\left(\mathrm{H}_{2} \mathrm{O}\right)^{c} \quad(\mathbf{2 7 8})$ or $(\mathrm{OPO})^{f} \mathrm{~V}^{\mathrm{V}}\left(\eta^{2}-\mathrm{O}_{2}\right)^{c}\left(\mathrm{H}_{2} \mathrm{O}\right)_{2}{ }^{s t}(\mathbf{4 0 9})$, is directly converted into a (OPO) $\mathrm{V}^{\mathrm{V}}$ species by protonating the peroxide ligand off, releasing $\mathrm{H}_{2} \mathrm{O}_{2}$. The released $\mathrm{H}_{2} \mathrm{O}_{2}$ can then coordinate with another equivalent of $(\mathrm{OPO}) \mathrm{V}^{\mathrm{III}}$ to form a $(\mathrm{OPO}) \mathrm{V}^{\mathrm{III}}(\mathrm{HOOH})$ species, which can be intramolecularly converted a second $(\mathrm{OPO}) \mathrm{V}^{\mathrm{V}}$ species. Thus, one equivalent of peroxide results in two equivalents of starting species 6 being regenerated. The lowest energy pathway we found for this protonation/reoxidation is shown in Scheme 7. A more detailed treatment is given in the supporting information, section A.

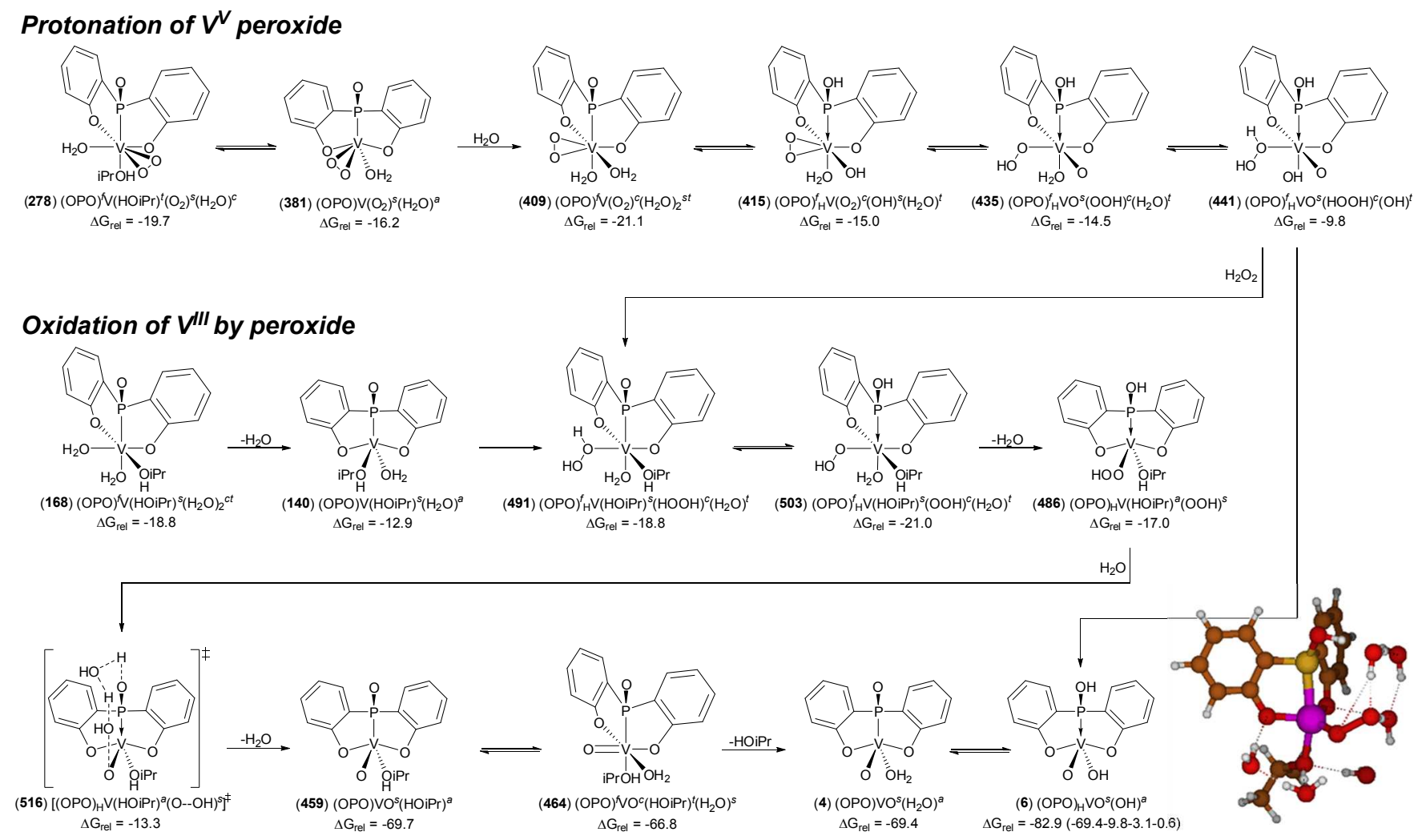

Scheme 7. Reforming the starting species 6 from the $(O P O)^{f} V^{V}$ peroxides 278 and/or 409 . In the top row, the peroxide is protonated off, forming one equivalent each of 6 and $\mathrm{H}_{2} \mathrm{O}_{2}$. In the second and third rows, $\mathrm{H}_{2} \mathrm{O}_{2}$ oxidizes a $\mathrm{V}^{\mathrm{III}}$ species to form a second equivalent of 6. The geometry optimized structure of 516 is shown in the bottom right corner of the scheme. All $\mathrm{V}^{\mathrm{III}}$ species shown are triplets, and all $\Delta G_{\text {rel }}$ values are in $\mathrm{kcal} / \mathrm{mol}$ and relative to 6 at the beginning of the reaction. Note that $\Delta G_{\text {rel }}$ for 6 is calculated from the sum of $\Delta G_{\text {rel }}$ 's for 4 and 441 plus the $-3.1 \mathrm{kcal} / \mathrm{mol}$ free energy change of the reaction $441 \rightarrow 6+\mathrm{H}_{2} \mathrm{O}_{2}$ and the $-0.6 \mathrm{kcal} / \mathrm{mol}$ free energy change of the reaction $4 \rightarrow 6$. In addition, $\Delta G=-82.9 \mathrm{kcal} / \mathrm{mol}$ for the overall reaction $2 \mathrm{iPrH}$ $+$ $\mathrm{O}_{2}$ 2iPrOH.

We see from Scheme 7 that it is easier to protonate the peroxide off 409 than 278; consequently, 278 is first converted to 409 by releasing HOiPr in exchange for an aqua ligand. The highest point along the reaction is the protonation step that forms the $\mathrm{HOOH}$ complex $(\mathrm{OPO})_{\mathrm{H}}^{f} \mathrm{~V}^{\mathrm{V}} \mathrm{O}^{s}(\mathrm{HOOH})^{c}(\mathrm{OH})^{t}(\mathbf{4 4 1})$, which then releases hydrogen peroxide to form the first equivalent of starting complex 6. In the second half of Scheme 7, the released $\mathrm{H}_{2} \mathrm{O}_{2}$ reacts with $\mathrm{V}^{\mathrm{III}}$ species 140, ultimately forming a second equivalent of $\mathbf{6}$.

\section{DISCUSSION}

In our previous report, ${ }^{7}$ we showed that the (OPO)V system is able to activate alkanes. We confirm this in our current report, showing that $(\mathrm{OPO})_{\mathrm{H}} \mathrm{V}^{\mathrm{V}} \mathrm{O}^{s}(\mathrm{OH})^{a}(6)$ is able to activate propane with a facile barrier of $25.2 \mathrm{kcal} / \mathrm{mol}$ (Scheme 3 ), and the iso- propyl radical is expected to rebound to form a triplet (OPO) $\mathrm{V}^{\mathrm{III}}(\mathrm{OiPr})$ species (Scheme 4).

In considering how the triplet $(\mathrm{OPO}) \mathrm{V}^{\mathrm{III}}(\mathrm{OiPr})$ species $\mathbf{1 6 8}$ may release the HOiPr product and reform the starting species 6, we considered two possible reoxidation routes:

- $\quad$ through a temporary dimer with a bridging peroxide moiety (457, Scheme 6), or

- through a two-step process consisting of peroxide protonation followed by a second oxidation (516, Scheme 7).

These two possibilities are compared in Figure 4, with dimerization pathway shown in red and protonation/oxidation in blue. 


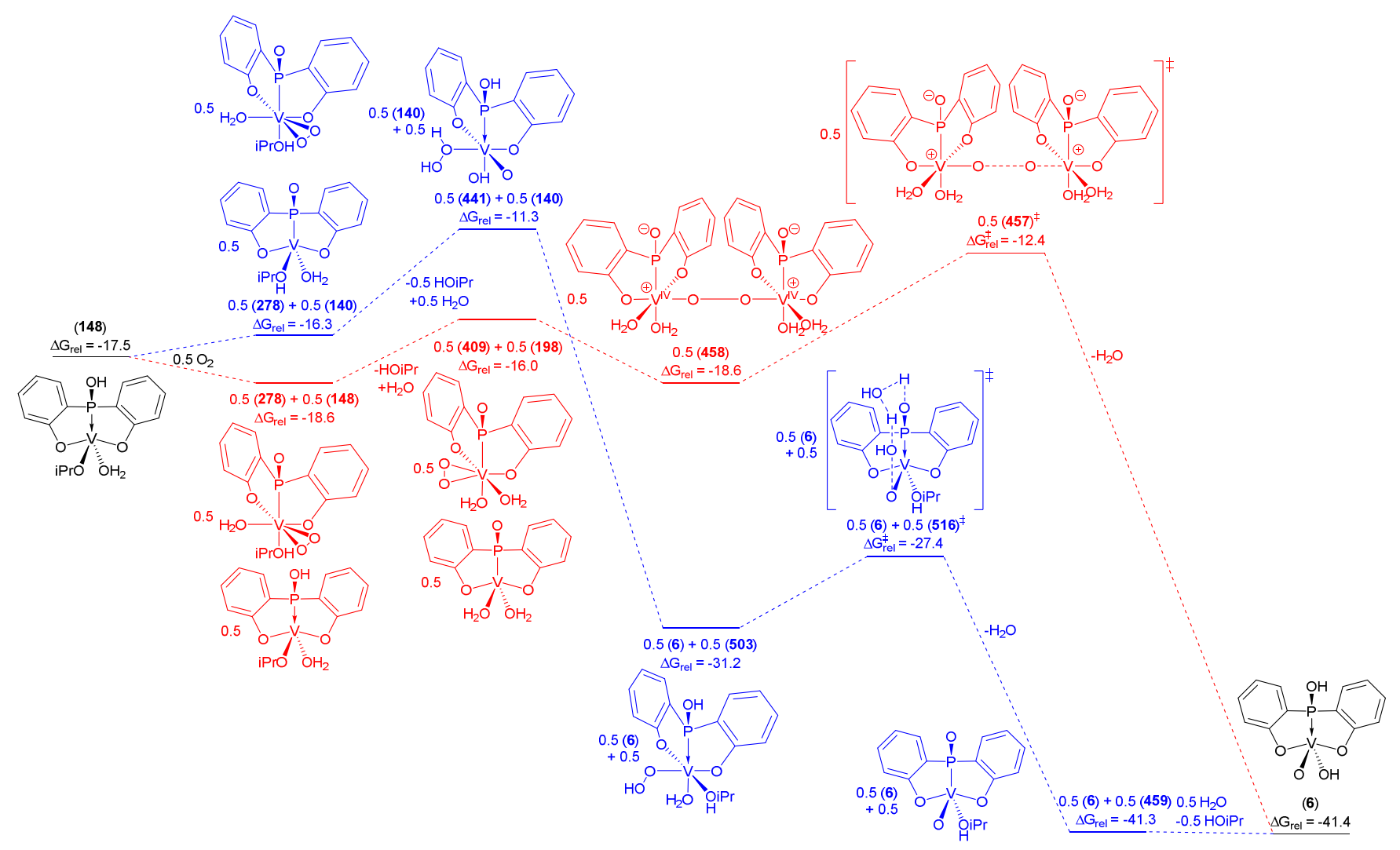

Figure 4. The energy landscape for the reoxidation of the $(\mathrm{OPO}) \mathrm{V}^{\mathrm{III}}(\mathrm{OiPr})$ species $\mathbf{1 4 8}$ to form the HOiPr product and reform the starting complex 6. Two possible pathways are shown: dimerization in red, and protonation/oxidation in blue. All numbers in kcal/mol and at $1 \mathrm{M}$. Only the energetics for species $\mathbf{4 5 8}$ and $\mathbf{4 5 7}$ in the red pathway are expected to be affected by concentration. At concentrations below 0.16 $\mathrm{M}$, the blue pathway (two-step protonation followed by a second oxidation) is expected to be more favorable.

The first thing to note from Figure 4 is that neither possibility is rate-determining; the barriers in each case are still smaller than the barriers for initial propane $\mathrm{C}-\mathrm{H}$ activation as in Scheme 3. The second thing to note is that the dimerization pathway has its highest energy in the $\mathrm{O}-\mathrm{O}$ bond-breaking transition state (457), whereas the protonation/oxidation pathway has its highest energy in the initial protonation step (441).

However, the most important aspect of Figure 4 is which pathway is more likely. Looking only at the numbers, it appears that the dimerization pathway in red is slightly more favorable $(-12.4 \mathrm{kcal} / \mathrm{mol}$ for 457 versus $-11.3 \mathrm{kcal} / \mathrm{mol}$ for 441). However, we caution that these numbers have not been adjusted for concentration. If the concentration of $\mathrm{V}$ is at catalytic amounts rather than 1 molar, we expect the dimerization pathway to increase in energy relative to the protonation/oxidation pathway since it involves a bimolecular mechanism. Indeed, for every 10 -fold reduction in V concentration we expect the energy of the dimerization pathway to increase by $1.36 \mathrm{kcal} / \mathrm{mol}$ at room temperature. ${ }^{33}$ Hence, we consider the protonation/oxidation pathway to be more likely in real conditions, with vanadium concentrations below 0.16 molar.

One final point we wish to address is the synthetic feasibility of our complex. Towards this end we have proposed several synthetic strategies to our resting state $\mathbf{6}$, using common synthetic techniques with literature precedent. Our synthetic proposals may be found in Section $\mathrm{C}$ of the supporting information.

\section{CONCLUSIONS}

In this report, we show that the bis(2-phenoxyl)phosphinite tridentate pincer ligand (OPO) $\kappa$-P coordinated onto vanadium is quite facile for activating propane, to catalyze its monoxygenation with dioxygen to isopropanol. We show that $\mathrm{C}-\mathrm{H}$ activation occurs via the reduction-coupled oxo activation (ROA) mechanism, which is the rate-determining step with $\Delta G^{\sharp}=25.2 \mathrm{kcal} / \mathrm{mol}$. We also show that the catalytic cycle is completed by dioxygen reoxidation of the resulting $\mathrm{V}^{\mathrm{III}}$ species, via the formation of a vanadium peroxide species followed by protonation and a second oxidation (or dimerization for high concentrations). Although we focus here on propane activation and oxidation, we expect very similar cycles to apply for other alkanes as well, including ethane and butane. We consider this catalytic system to be very promising for low temperature selective oxidations of alkanes with functionalization and catalyst regeneration using molecular $\mathrm{O}_{2}$. This is a promising system for synthesis and characterization.

\section{AUTHOR INFORMATION}

\section{Corresponding Author}

* To whom correspondence should be addressed. Email: wag@wag.caltech.edu

\section{Funding Sources}

This research was supported by NSF (CHE-1214158).

\section{ASSOCIATED CONTENT}


Supporting Information. Additional reaction pathways, as well as tables of energetics of all species studied. This material is available free of charge via the Internet at http://pubs.acs.org.

\section{ACKNOWLEDGMENT}

This research was supported by NSF (CHE-1214158).

\section{ABBREVIATIONS}

(OPO), bis(2-phenoxyl)phosphinite; ROA, reduction-coupled oxo activation; DFT, density functional theory

\section{REFERENCES}

1. Centi, G.; Trifiro, F.; Ebner, J. R., Franchetti, V. M. Chem. Rev. 1988, 88, 55-80.

2. B. K. Hodnett, Heterogeneous Catalytic Oxidation. Wiley: New York, 2000.

3. Cheng, M.-J.; Goddard, W. A. III. J. Am. Chem. Soc. 2013, $135,4600-4603$.

4. Schuurman, Y.; Gleaves, J. T. Ind. Eng. Chem. Res. 1994, 33, 2935-2941.

5. Hutchings, G. J.; Desmartinchomel, A.; Olier, R.; Volta, J. C. Nature 1994, 368, 41-45.

6. a. Cheng, M.-J.; Goddard, W. A. III; Fu, R. Top. Catal. 2014, 57, 1171-1187; b. Cheng, M.-J.; Goddard, W. A. III; $\mathrm{Fu}, \mathrm{R}$. Methods for providing bond activation catalysts and related catalysts, systems, and methods. U.S. Patent 9,308,525, April 12, 2016.

7. Cheng, M.-J.; Fu, R.; Goddard, W. A. III. Chem. Commun. 2014, 50, 1748-1750.

8. a. Marino, N.; Hanson, S. K.; Müller, P.; Doyle, R. P. Inorg. Chem. 2012, 51, 10077-10079; b. Herron, N.; Thorn, D. L.; Harlow, R. L.; Coulston, G. W. J. Am. Chem. Soc. 1997, 119, 7149-7150; c. Solis-Ibarra, D.; Silvia, J. S.; Jancik, V.; Cummins, C. C. Inorg. Chem. 2011, 50, 9980 9984.

9. Pan, B. F.; Bezpalko, M. W.; Foxman, B. M.; Thomas, C. M. Organometallics 2011, 30, 5560-5563.

10. Derrah, E. J.; Martin, C.; Mallet-Ladeira, S.; Miqueu, K.; Bouhadir, G.; Bourissou, D. Organometallics 2013, 32, $1121-1128$.

11. Derrah, E. J.; Ladeira, S.; Bouhadir, G.; Miqueu, K.; Bourissou, D. Chem. Commun. 2011, 47, 8611-8613.

12. Pan, B. F.; Bezpalko, M. W.; Foxman, B. M.; Thomas, C. M. Dalton Trans. 2012, 41, 9083-9090.

13. Bauer, R. C.; Gloaguen, Y.; Lutz, M.; Reek, J. N. H.; de Bruin, B.; van der Vlugt, J. I. Dalton Trans. 2011, 40, $8822-8829$.

14. Mazzeo, M.; Lamberti, M.; Massa, A.; Scettri, A.; Pellecchia, C.; Peters, J. C. Organometallics 2008, 27, 57415743.

15. Gloaguen, Y.; Jacobs, W.; de Bruin, B.; Lutz, M.; van der Vlugt, J. I. Inorg. Chem. 2013, 52, 1682-1684.

16. Mazzeo, M.; Strianese, M.; Kuhl, O.; Peters, J. C. Dalton Trans. 2011, 40, 9026-9033.
17. Blanksby, S. J.; Ellison, G. B. Acc. Chem. Res. 2003, 36 255-263.

18. Bochevarov, A. D.; Harder, E.; Hughes, T. F.; Greenwood, J. R.; Braden, D. A.; Philipp, D. M.; Rinaldo, D.; Halls, M. D.; Zhang, J.; Friesner, R. A. Intl. J. Quant. Chem. 2013, $113,2110-2142$.

19. a. Tannor, D. J.; Marten, B.; Murphy, R.; Friesner, R. A.; Sitkoff, D.; Nicholls, A.; Ringnalda, M. N.; Goddard, W. A. III; Honig, B. J. Am. Chem. Soc. 1994, 116, 1187511882; b. Marten, B.; Kim, K.; Cortis, C.; Friesner, R. A.; Murphy, R. B.; Ringnalda, M. N.; Sitkoff, D.; Honig, B. J. Phys. Chem. 1996, 100, 11775-11788.

20. a. Becke, A. D. Phys. Rev. A 1998, 38, 3098-3100; b. Becke, A. D. J. Chem. Phys. 1993, 98, 5648-5652; c. Lee, C. T.; Yang, W. T.; Parr, R. G. Phys. Rev. B 1988, 37, 785789.

21. Grimme, S.; Antony, J.; Erlich, S.; Krieg, H. J. Chem. Phys. 2010, 132, 154104.

22. a. Hehre, W. J.; Ditchfield, R.; Pople, J. A. J. Chem. Phys. 1972, 56, 2257-2261; b. Francl, M. M.; Pietro, W. J.; Hehre, W. J.; Binkley, J. S.; Gordon, M. S.; Defrees, D. J.; Pople, J. A. J. Chem. Phys. 1982, 77, 3654-3665.

23. a. Hay, P. J.; Wadt, W. R. J. Chem. Phys. 1985, 82, 299310; b. Melius, C. F.; Goddard, W. A. III; Phys. Rev. A 1974, 10, 1528-1540; c. Melius, C. F.; Olafson, B. D.; Goddard, W. A. III; Chem. Phys. Lett. 1974, 28, 457-462.

24. Martin, J. M. L.; Sundermann, A. J. Chem. Phys. 2001, 114, 3408-3420.

25. a. Clark, T.; Chandrasekhar, J.; Spitznagel, G. W.; Schleyer, P. V. J. Comput. Chem. 1983, 4, 294-301; b. Krishnan, R.; Binkley, J. S.; Seeger, R.; Pople, J. A. J. Chem. Phys. 1980, 72, 650-654.

26. Pipek, J.; Mezey, P. G. J. Chem. Phys. 1989, 90, 4916 4926.

27. Wertz, D. H. J. Am. Chem. Soc. 1980, 102, 5316-5322.

28. Chase, M. W. Jr. NIST-JANAF Themochemical Tables, Fourth Edition, J. Phys. Chem. Ref. Data, Monograph 9, 1998, 1-1951.

29. a. Goldstein, E.; Beno, B.; Houk, K. N. J. Am. Chem. Soc. 1995, 118, 6036-6043; b. Yamanaka, S.; Kawakami, T.; Nagao, K.; Yamaguchi, K. Chem. Phys. Lett. 1994, 231, 25-33; c. Yamaguchi, K.; Jensen, F.; Dorigo, A.; Houk, K. N. Chem. Phys. Lett. 1988, 149, 537-542; d. Cramer, C. J.; Dulles, F. J.; Giesen, G. J.; Almlöf, J. Chem. Phys. Lett. 1995, 245, 165-170.

30. Tissandier, M. D.; Cowen, K. A.; Feng, W. Y.; Gundlach, E.; Cohen, M. H.; Earhart, A. D.; Coe, J. V.; Tuttle, T. R. Jr. J. Phys. Chem. A 1998, 102, 7787-7794.

31. T. L. Hill, An Introduction to Statistical Thermodynamics, Dover, New York, 1986; p. 84.

32. Cheng, M.-J.; Chenoweth, K.; Oxgaard, J.; van Duin, A.; Goddard, W. A. III. J. Phys. Chem. C 2007, 111, 51155127.

33. $1.36 \mathrm{kcal} / \mathrm{mol}$ is the value of $k T \ln (10)$ at $298.15 \mathrm{~K}$. 
SYNOPSIS TOC (Word Style "SN_Synopsis_TOC"). If you are submitting your paper to a journal that requires a synopsis graphic and/or synopsis paragraph, see the Instructions for Authors on the journal's homepage for a description of what needs to be provided and for the size requirements of the artwork.

Authors are required to submit a graphic entry for the Table of Contents (TOC) that, in conjunction with the manuscript title, should give the reader a representative idea of one of the following: A key structure, reaction, equation, concept, or theorem, etc., that is discussed in the manuscript. Consult the journal's Instructions for Authors for TOC graphic specifications.

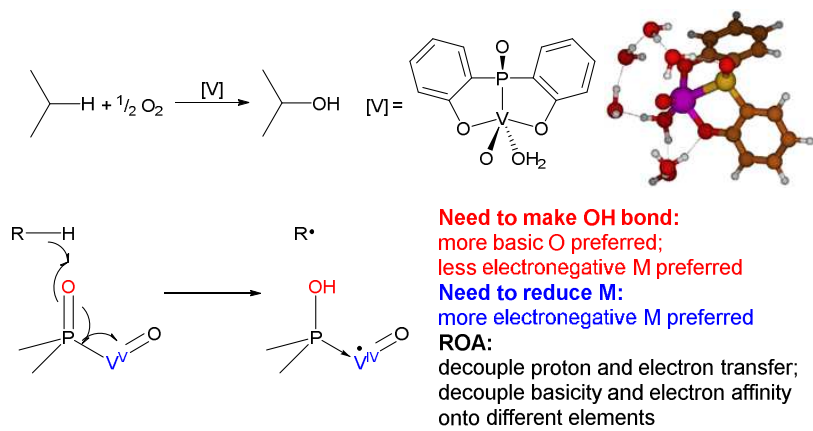

